\title{
Holistic well-being of Japanese retirees in Malaysia
}

\section{Jeffrey Lawrence D'Silva}

Institute for Social Science Studies,

Universiti Putra Malaysia

Malaysia

jld@upm.edu.my

https:/ / orcid.org/0000-0002-5673-8712

\author{
Asnarulkhadi Abu Samah \\ Institute for Social Science Studies, \\ Universiti Putra Malaysia \\ Malaysia \\ asnaru@upm.edu.my
}

Abstract. The current era of extensive use of information and communication technology and globalization brought the mankind to pay attention to the wellbeing of people as it is paramount for sustainable development of communities. Accordingly, numerous discussions were put forward to conceptualize well-being as such. Judging from the literature, holistic well-being is deemed as a better form of measuring well-being as it incorporates both objective and subjective dimensions. The aim of this study is to examine the holistic well-being of Japanese retirees residing in Malaysia. Data were collected from 278 retirees via a pick-anddrop method as well as face-to-face interviews. The findings show that the holistic well-being of Japanese retirees in Malaysia is $56.3 \%$. Besides, the study has identified that these retirees scored as the highest the dimensions of communication technologies and lifestyle. On the other hand, the lowest scores got the dimensions of political and physical facilities. It is proposed that to further enhance the international retirement migration, particularly in the Malaysian context, political stability and good physical facilities are the pertinent factors that need to be emphasized.

Keywords: holistic well-being, objective dimension, subjective dimension, retirees, Malaysia.

JEL Classification: I3, J15, J14

Received:

March, 2018

1st Revision:

June, 2018

Accepted:

July, 2018

DOI:

10.14254/2071-

$8330.2018 / 11-3 / 8$ 


\section{INTRODUCTION}

Over the years massive changes have been occurring in the development of communities as a result of immense usage of information and communication technology and the advent of first industrial and then also postindustrial revolutions. Globally, Sustainable Development Goals 2030 has 17 aims, namely: (1) no poverty, (2) zero hunger, (3) good health and well-being, (4) quality education, (5) gender equality, (6) clean water and sanitation, (7) affordable and clean energy, (8) decent work and economic growth, (9) industry, innovation and infrastructure, (10) reduced inequalities, (11) sustainable cities and communities, (12) responsible consumption and production, (13) climate action, (14) life below water, (15) life on land, (16) peace, justice and strong institutions, and (17) partnerships for the goals, and these goals together stand as a guide for the countries to diminish poverty, protect the Earth and make sure the people prosper in their life. In line with these goals, the well-being of communities continues to play a pivotal role for policy-makers to safeguard the interests of different communities as well as to eradicate the inequality in resources' supply and growth among communities.

An amazing fact regarding the concept of well-being is that social scientists are still grappling to determine the appropriate measurement mechanisms that will reflect the well-being of communities and there is a plethora of literature studies discussing well-being and happiness (D'Silva et al., 2017). Furthermore, in some studies, individual well-being has been linked with environment comfort factors (Mishchuk \& Grishnova, 2015). Past literature revealed that a number of ways were used to measure wellbeing (Ivkovic, Ham \& Mijoc, 2014; Diener \& Suh, 1997; Diener et al., 1999). Aristotle, for instance, sees well-being in the form of attaining personal development in the domains of knowledge, money, health, and bonding with societies. As time passeв by, in the $18^{\text {th }}$ century, life happiness of individuals became the indicator of well-being. Consequently, understanding of well-being has further developed as researchers coined the concept of objective and subjective approaches. The objective approach is generally applied as a tool to measure well-being across different nations and/or time points. On the other hand, the subjective approach is designed to identify the causes of well-being.

An interesting phenomenon occurring today in relation to community well-being is the well-being of individuals who chose to retire in a foreign country, this is also known as international retirement migration. These individuals prefer to live in a foreign country during their retirement period of life due to a number of reasons such as accommodative public policies, excellent healthcare facilities, intercultural training schemes and unique features of host nations etc. (Ashton \& Scott, 2017). Foreign retirees also appreciate the convenience, especially in gaining their visas. In line with this, the Malaysian government has carried out a program named "Malaysia My Second Home" (MMSH) that accommodates foreigners to stay in Malaysia with a ten-year renewable visa and some other benefits.

According to the MMSH statistics, there are the total of 34,591 participants in the program, from 2002 to June 2017. Malaysia government lists 15 benefits of residing in Malaysia, namely, the people and the language, the weather, the cost of living, economic and political stability, infrastructure, the food, shopping, natural beauty, sports, other entertainments, telecommunications, safety and healthcare, location, education, and seeing friends and relatives. Even though there are numerous benefits provided by the host country in this case, the holistic well-being of these retirees is yet to be determined. Hence, the aim of this study is to determine the holistic well-being of Japanese retirees in Malaysia and the outcome of this study will provide better and more detailed understanding of the phenomenon of foreigners staying in Malaysia once they are retired. 


\section{LITERATURE REVIEW}

\subsection{INDICATORS OF HOLISTIC WELL-BEING}

The conceptual understanding of well-being has evolved over the years. In general, based on the existing literature, the measurement of well-being is done using the objective and subjective approaches. Initially, the objective approach employs gross domestic product (GDP) and wealth as the indicators of well-being and community well-being is measured based on nation's GDP. However, there are many critiques on the usage of GDP as an indicator of the well-being of society as it possesses many limitations. The main argument put forward is the inability of GDP to capture on wealth distribution among the various communities. Development economist Amartya Sen states that the GDP is incapable to measure the distribution of wealth and inequality among the different individuals in society. Consequently, it was proposed that the well-being of society should encompass social and economic indicators that are quantifiable (Sen, 1999), namely, health, housing, education, social relationships, political voice, safety, and so on. All these dimensions are considered as the objective approach to measuring well-being. Since there are many dimensions that could be used to measure well-being using the objective approach, there exists disagreement among countries on the appropriate dimensions. However, generally, most countries accept the dimensions of income, health, education, and security as the indicators of objective well-being.

Another mechanism to measure well-being emerged with the conceptualization of subjective wellbeing. This new science of well-being developed with the work carried out by Kahneman, Diener, and Schwarz (1999) states that individual's well-being is based one's assessment of the wellness they are experiencing in their life. Thus, things that bring goodness to one's life will have an impact on one's wellbeing (Tay et al., 2015; Cummins \& Nistico, 2002). Besides, subjective well-being was measured using both individual and national dimensions (Helliwell, 2002).

Subjective well-being is also measured using the evaluative well-being and affective well-being. Eger and Maridal (2015) state that evaluative well-being and affective well-being is seen as a continuum, with life satisfaction which is perceived as a long-term and deeper happiness on the evaluative side and immediate happiness on the affective side.

Since the emergence of subjective well-being, continuous debates occur among social scientists on the appropriate measurement of well-being (Diaz \& Bui, 2017). Cummins et al. (2003) mentioned that the dimension of wealth was considered the pertinent dimension to measure the goodness of society. However, Gasper (2004) argued that both objective well-being and subjective well-being dimensions will portray a better picture of the well-being of society. Bohnke and Kohler (2008) state that there are two approaches to the study of well-being namely the subjective and objective approach. In the subjective approach, several factors $(\mathrm{X} 1, \mathrm{X} 2, \mathrm{X} 3 \ldots)$ have an impact towards well-being and this, in turn, will influence the subjective well-being. On the other hand, the objective approach states that well-being is a summation of several factors $(\mathrm{X} 1, \mathrm{X} 2, \mathrm{X} 3 \ldots)$ and subjective well-being. Thus, it can be seen based on both these approaches the objective approach sees subjective well-being as another indicator that has an influence on well-being while the subjective approach states that the indicators of well-being influence happiness and life satisfaction.

Another view on the classification of the well-being concepts is portrayed by Eger and Maridal (2015). In their opinion, the underlying concepts on the subjective variables of well-being are divided into two parts, namely, (a) life satisfaction, and (b) happiness. In the life satisfaction component, the level of perception is in terms of cognitive, evaluative, reflective and long-term and the potential measurements are the Cantril's self-anchoring ladder or questionnaire. On the other hand, in the happiness component, the level of perception is measured in terms of emotional, mood or affect-based, sensory and short-term, and the potential measurements are day reconstruction method and positive and negative affect schedule. Eger and 
Maridal (2015) further add that the objective variables of well-being are conceptualized into two parts, namely, livability dimensions (environmental, external factors) and lifeability dimensions (individual, internal factors). The elements to measure the concept of livability dimensions are friends, family, peace, freedom, health, income, wealth, opportunity, etc while the elements to measure the lifeability dimensions are a degree of purpose and meaning to life, attitudes, life choices, and heredity. Among the potential measurements for the livability dimensions are numerical indicators of income, health, family, crime, etc. and for lifeability dimensions are brain-scanning, revealed preferences and questionnaires.

Based on the above arguments and the continuous discussions on the appropriate mechanism to measure well-being, it is proposed that well-being could encompass of both the objective and subjective dimensions and it could be conceptualized as the holistic well-being of the individual. The basis for the connotation of this holistic well-being is that the objective well-being will provide data on individuals' current 'assets' and 'liabilities' while the subjective well-being will provide individuals' input on their current satisfaction towards life. By reconciling the dimensions of objective and subjective well-being, it will provide a more accurate and holistic measurement of an individual's good and satisfying life. Furthermore, if both these approaches are paired appropriately, it will overcome one another's weaknesses and offer a more holistic understanding of the concept of well-being.

\subsection{HOLISTIC WELL-BEING FOR RETIREES IN A FOREIGN LAND}

As discussed earlier, the holistic well-being will constitute both the objective and subjective dimensions from the perspective of individuals and this mechanism will reflect the 'true' well-being based on actual achievement and experiences of individuals. Next is the question of getting the appropriate indicators to measure both these objective and subjective dimensions. Bohnke and Kohler (2008) state that the objective dimensions contain the attributes of income, education, health, life-style and social relationships. On the other hand, there is a variation on the indicators of subjective well-being based on the studies carried out by the different researchers. Yassin et al. (2015) argue that there are a number of dimensions within the scope of subjective well-being, namely, economic, environment, educational, political, physical health, cultural, psychological, physical facilities, safety, work-life balance that has an impact on individual wellbeing. Western and Tomszewski (2016) mentioned eight variables to measure well-being and the dimensions are subjective well-being, income, finance, health, material deprivation, leisure time, and having contacts with families and friends. Furthermore, Verduyn et al. (2017) placed much importance on digital communication and social networking as a mechanism to boost subjective well-being.

In the context of retirees living in a foreign land, it is proposed that the holistic well-being on the objective dimension will constitute individuals achievement for the indicators of income, education, health, life-style and social relationship. While the subjective dimension will picture individuals experiences toward indicators that they have either direct or no control of them. The indicators that each individual will have a direct control are economic, education, physical health, spiritual and social. While the indicators that they do not have control are the environment, safety, physical facilities, political and communication. A summation of all these indicators will lead towards a holistic measurement of well-being and is poised to reflect an optimized measurement of well-being

\section{METHODOLOGY}

The method contains detail explanation on five components, namely, (1) the research design, (2) instrumentation, (3) sampling, (4) data collection, and (5) data analysis. The main aim of the study is to determine the holistic well-being of Japanese retirees residing in Malaysia. Consequently, the study employed the quantitative field survey method to achieve this objective. 
The development of the study instrument took a period of one-month. Firstly, previous literature such as the Well-being Deutsche Bank, Legatum Prosperity Index, Well-being New Economic Foundation (NEF), Well-being OECD, Malaysian Well-being Index, and Yassin et al. (2015) was used to develop the items for the determined dimensions of well-being for retirees. These items went through the process of the face and content validity to ensure its relevance. Eventually, there were 13 items to measure the objective dimension comprising of items related to income, education and skills, housing, life-style, and communication technology. Meanwhile, there were 10 dimensions of the subjective well-being and these dimensions were social, spiritual, education, political, physical health, economic, public safety, physical facilities, environment, and communications.

The population of the Japanese retirees living in Malaysia is around 4,000. These retirees are living in Malaysia based on Malaysia My Second Home program. Based on a confidence level $0 f 95 \%$ and confidence interval of 5 , the sample size required to represent the population is 351 . Previous studies on the population of retirees living in foreign lands have identified that it is difficult to obtain the required sample due to security and privacy reasons. In line with this, despite exhaustive attempts, the study managed to obtain a sample of 278. Even though the number is less than the minimum required, the findings are still relevant since this study is descriptive in nature and the aim is to acquire the holistic well-being index of Japanese retirees living in Malaysia.

The data collection was carried out for eight months in 2017 with the assistance from a number of Japanese associations and clubs. The questionnaire was translated into the Japanese language to ease the data collection process. Enumerators that are able to speak Japanese aided in the data collection process. Since the data collection employed a face-to-face approach, the rate of the complete questionnaire was high. Only three questionnaires were excluded due to insufficient information.

After obtaining the data, it was entered into the SPSS software for analysis. Data computation was done to reflect the variables based on a five-point scale. For the objective dimension, the dimensions were calculated based on the following formula:

a) net income was computed by looking at the difference between income and expenditure,

b) education was computed based on their level of education and acquired skills

c) housing was calculated based on the type of their current house ranging from single-storey house to bungalow house

d) life-style was computed based on the items pertaining to exercise, sleep, smoking, drinking alcohol, and involvement in family and voluntary activities

e) health was evaluated based on having a chronic illness, and visits to hospitals/private medical practitioners

f) communication technology was computed on their access and usage of media

On the other hand, the subjective dimension had ten variables and each variable constituted between 3-5 items with a five-point scale (ranging from strongly disagree to strongly agree). The reliability test for all these variables exceeds the minimum threshold of .7 indicating that the items are reliable.

Then, the computation of both the objective and subjective dimensions was carried out that reflects the current status of the objective and subjective well-being of Japanese retirees in Malaysia.

\section{EMPIRICAL RESULTS AND DISCUSSION}

The section depicts the results of the study on the holistic well-being of Japanese retirees living in Malaysia. The holistic well-being is the summation of scores obtained from both the objective and subjective dimensions of well-being. Table 1 shows the scores obtained from the objective dimension and the mean 
score was 3.1 ( $\mathrm{SD}=.46$ ). Past studies carried out by Yassin et al. (2015) on Malaysian police retirees yielded a mean score of $3.3(\mathrm{SD}=.34)$.

Table 1

Objective Well-being of Japanese Retirees in Malaysia

\begin{tabular}{|l|c|c|c|}
\hline & N & Mean & Std. Deviation \\
\hline Objective dimension & 278 & 3.1 & .46 \\
\hline
\end{tabular}

Source: own research

Next, as in Table 2, the objective well-being of these retirees is captured according to the different levels. The data showed that majority of them are at the moderate level (88.5\%) followed by high level (6.1\%) and low level (5.4\%). In comparison, Yassin et al. (2015) study showed that $82.9 \%$ of the police retirees were at the moderate level, followed by high level (16.0\%) and low level (1.2\%).

Table 2

Objective Well-being Level of Japanese Retirees in Malaysia

\begin{tabular}{|ll|c|c|c|c|}
\hline & Frequency & Percent & Valid Percent & Cumulative Percent \\
\hline Valid & Low & 15 & 5.4 & 5.4 & 5.4 \\
& Moderate & 246 & 88.5 & 88.5 & 93.9 \\
& High & 17 & 6.1 & 6.1 & 100 \\
\hline
\end{tabular}

Source: own research

Table 3 further explains the contribution of each of the objective dimension. It is pertinent that the objective well-being of the Japanese retirees is vastly contributed by their social relationships with the digital technology. This is followed by the healthy life-style practices in terms of exercise, refraining from smoking and drinking alcohol, having adequate hours of sleep, cordial relationships with family members and friends as well as participating actively in volunteerism activities. However, these retirees did not score well in education and acquiring new skills as this is expected due to their age.

Table 3

Dimensions of Objective Well-being of Japanese Retirees in Malaysia

\begin{tabular}{|l|c|c|}
\hline & Mean & Std. Deviation \\
\hline Income & 2.4 & 1.78 \\
Education/skills & 2.2 & 1.13 \\
Housing & 2.8 & .49 \\
Life-style & 2.7 & 1.31 \\
Communication technology & 4.9 & .53 \\
\hline
\end{tabular}

Source: own research

The following result is on the subjective well-being of Japanese retirees residing in Malaysia. Table 4 shows that the mean score of the subjective well-being of these retirees stands at 3.4 ( $\mathrm{SD}=.39)$. As a 
comparison, the mean score on the subjective well-being of police retirees in Malaysia was higher at 3.7 (SD=.36) (Yassin et al., 2015).

Table 4

Subjective Well-being of Japanese Retirees in Malaysia

\begin{tabular}{|l|c|c|c|}
\hline & N & Mean & Std. Deviation \\
\hline Subjective dimension & 278 & 3.4 & .39 \\
\hline
\end{tabular}

Source: own research

Further analysis as in Table 4 on the levels of subjective well-being of these retirees showed that $81.3 \%$ are at the moderate level while $18.7 \%$ is at the high level. The study on the Malaysian police retirees showed that $59.3 \%$ are at the high levels and $40.7 \%$ are at the moderate level.

Table 5

Subjective Well-being Level of Japanese Retirees in Malaysia

\begin{tabular}{|cc|c|c|c|c|}
\hline & Frequency & Percent & Valid Percent & Cumulative Percent \\
\hline Valid & Moderate & 226 & 81.3 & 81.3 & 81.3 \\
& High & 52 & 18.7 & 18.7 & 100 \\
\hline
\end{tabular}

Source: own research

Table 6 shows the contributing dimensions on the subjective well-being of Japanese retirees in Malaysia. It is evident that the contributing domains are social, spiritual and economic. On the other hand, the least contributing domains are politics and physical facilities. Making a comparison between the current study and Yassin et al.'s (2015) study, the similarity is that social dimension remains the highest in both the studies. Conversely, even though economic dimension is among the top in the current study, it was among the bottom for the study on police retirees. Furthermore, political concern was not an issue for the police retirees but the Japanese retirees felt that the political dimension, as well as the physical facilities, need much improvement as these dimensions are affecting their subjective well-being.

Table 6

Dimensions of Subjective Well-being of Japanese Retirees in Malaysia

\begin{tabular}{|l|c|c|}
\hline & Mean & Std. Deviation \\
\hline Social & 3.9 & .76 \\
Spiritual & 3.7 & .52 \\
Education & 3.6 & .53 \\
Economy & 3.7 & .68 \\
Safety & 3.6 & .80 \\
Environment & 3.3 & .74 \\
Communications & 3.5 & .64 \\
Health & 2.9 & .67 \\
Physical facilities & 2.8 & .65 \\
Politics & 2.7 & .71 \\
\hline
\end{tabular}

Based on the above results, the holistic well-being can be computed by summing the scores obtained from both the objective and subjective well-being dimensions. The mean score for the objective well-being 
dimensions was 3.1 and placing this in the form of percentage it will be $52.5 \%$. On the other hand, the mean score for the subjective well-being dimension was 3.4 and transforming this into percentage it will be $60 \%$. This means overall the holistic well-being of the Japanese retirees staying in Malaysia is $56.3 \%$. This figure is slightly lower than what Yassin et al. (2015) study on the overall well-being of Malaysian police retirees $(62.9 \%)$. The current figure also shows that based on The Cantril Ladder Scale the Japanese retirees in Malaysia are neither thriving nor suffering and they rate their present life moderately.

\section{CONCLUSION}

This study provides a baseline information on the current status of the holistic well-being of Japanese retirees in Malaysia. Theoretically, this study provides a novel mechanism for measuring the concept of wellbeing with the introduction of holistic well-being that encompasses the summative scores of both objective and subjective well-being dimensions. The outcome of the study showed that these retirees are experiencing a moderate level of well-being and more efforts could be taken to bring them to the level of thriving. It is evident from the findings that to boost the holistic well-being of Japanese retirees in Malaysia, the various Japanese organizations in Malaysia could help to enhance the skills of these retirees via workshops and training programs. Equally important in the area of subjective well-being is the concerned faced by these retirees about the political situation in Malaysia as they perceive as unstable. Moreover, these Japanese retirees also felt that the physical facilities, particularly on public transportation, could be further improved to ease their mobility from one area to another. Despite some limitations in the study, the findings provide some insights for policy-makers and other interested organizations to take proactive measures that will further enhance the holistic well-being of Japanese retirees residing in Malaysia as well as boosting of longerstay of international tourists in Malaysian soil.

\section{ACKNOWLEDGEMENT}

The authors wish to acknowledge SUMITOMO Foundation for supporting this study.

\section{REFERENCES}

Ashton, A. S., \& Scott, N. (2017). International Retirement Migration and Thai Stakeholders' Views: A Japanese Case Study. Journal of Place Management and Development, 10(1), 7-22.

Bohnke, P., \& Kohler, U. (2008). Well-being and inequality (WZB Discussion Paper No. SP 12008-201).

Cummins, R. A., Eckersley, R., Pallan, J., Van Vugt, J., \& Misajon, R. (2003). Developing a national index of subjective well-being: The Australian Unity Well-being Index. Social Indicators Research, 64(1), 159-190.

Cummins, R. A., \& Nistico, H. (2002). Maintaining life satisfaction: The role of positive cognitive bias. Journal of Happiness Studies, 3(1), 37-69.

Diaz, T., \& Bui, N. H. (2017). Subjective Well-Being in Mexican and Mexican American Women: The Role of Acculturation, Ethnic Identity, Gender Roles, and Perceived Social Support. Journal of Happiness Studies, 18(2), 607-624.

Diener, E., \& Suh, E. (1997). Measuring quality of life: Economic, social, and subjective indicators. Social Indicators Research, 40(1-2), 189-216.

Diener, E., Suh, E. M., Lucas, R. E., \& Smith, H. L. (1999). Subjective well-being: Three decades of progress. Psychological Bulletin, 125(2), 276-302.

D'Silva, J. L., Yassin, S. M., Samah, A. A., \& Kamaruddin, N. (2017). An analysis on work happiness among university staff in a Malaysian context. International Journal of Applied Business and Economic Research, 15(16), 255-262.

Eger, R. J., \& Maridal, J. H. (2015). A statistical meta-analysis of the wellbeing literature. International Journal of Wellbeing, 5(2), 45-74. 
Gasper, D. (2005). Subjective and objective well-being in relation to economic inputs: puzzles and responses. Review of Social Economy, 63(2), 177-206

Helliwell, J. F. (2002). How's Life? Combining Individual and National Variables to Explain Subjective Well-Being (NBER Working Paper No. 9065). Cambridge, MA: National Bureau of Economic Research.

Ivković, A. F., Ham, M., \& Mijoč, J. (2014). Measuring objective well-being and sustainable development management. Journal of Knowledge Management, Economics and Information Technology, 4(2), 1-29.

Kahneman, D., Diener, E., \& Schwarz, N. (1999). Well-being: Foundations of hedonic psychology. New York, NY: Russell Sage Foundation.

Mishchuk, H., \& Grishnova, O. (2015). Empirical study of the comfort of living and working environment - Ukraine and Europe: comparative assessment. Journal of International Studies, 8(1), 67-80.

Sen, A. (1999). Freedom as development. New York, NY: Oxford University Press.

Tay, L., Kuykendall, L., \& Diener, E. (2015). Satisfaction and happiness-the bright side of quality of life. In W. Glatzer, L. Camfield, V. Moller, \& M. Rojar (Eds.), Global handbook of quality of life (pp. 839-853). Dordrecht, Netherlands: Springer.

Verduyn, P., Ybarra, O., Résibois, M., Jonides, J., \& Kross, E. (2017). Do Social Network Sites Enhance or Undermine Subjective Well-Being? A Critical Review. Social Issues and Policy Review, 11(1), 274-302.

Western, M., \& Tomaszewski, W. (2016). Subjective wellbeing, objective wellbeing and inequality in Australia. PloS One, 11(10), 1-20.

Yassin, S. M., Samah, A. A., D’Silva, J. L., Shaffril, H. A. M., \& Sahharon, H. (2015). Well-being Revisited: A Malaysian Perspective. Selangor: Poverty Eradication Foundation.

Yassin, S. M., Samah, A. A., Omar, S. Z., D’Silva, J. L., Ortega, A., \& Sulaiman, A. H. (2015). Final report study on the well-being of police retirees in Malaysia. Selangor: Yayasan Pengaman Malaysia. 